\title{
A Re-Examination of the Predictability of Economic Activity Using the Yield Spread
}

\author{
James D. Hamilton \\ Department of Economics, 0508 \\ University of California, San Diego \\ La Jolla, CA 92093-0508 \\ jhamilton@ucsd.edu \\ Dong Heon Kim \\ School of Economic Studies \\ University of Manchester \\ Manchester M13 9PL, U.K. \\ dongheon.kim@man.ac.uk
}

July 1999

Revised: January 2001 


\begin{abstract}
This paper revisits the yield spread's usefulness for predicting future real GDP growth. We show that the contribution of the spread can be decomposed into the effect of expected future changes in short rates and the effect of the term premium. We find that both factors are relevant for predicting real GDP growth but the respective contributions differ. We investigate whether the cyclical behavior of interest rate volatility could account for either or both effects. We find that while volatility displays important correlations with both the term structure of interest rates and GDP, it does not appear to account for the yield spread's usefulness for predicting GDP growth.
\end{abstract}

- JEL Classification: E32, E37, E43 


\section{INTRODUCTION}

A large literature has examined variables that help predict the business cycle. Interest rates and interest rate spreads - that is, differences between interest rates on alternative financial assets — have attracted considerable attention from market analysts, policy-makers and academic economists. Stock and Watson (1989) found that two interest rate spreads- the difference between the 6-month commercial paper rate and 6-month Treasury bill rate, and the difference between the 10-year and 1-year Treasury bond rates-were important to include in their newly constructed index of leading economic indicators. Since then, various authors have investigated a variety of alternative interest rates and spreads.

The usefulness of the yield spread between long- and short-term interest rates for forecasting future economic activity has been particularly well established. Harvey $(1988,1989)$ has shown that there is information about future consumption and output growth in the real term structure. Estrella and Hardouvelis (1991) documented that the yield spread between the 10-year Treasury bond rate and the 3-month Treasury bill rate is a useful predictor of future growth in output, consumption and investment, and the probability of a recession. Plosser and Rouwenhorst (1994) examined the information contained in the term structure about future real economic growth in three industrialized countries. They found that the term structure has significant predictive power for long-term economic growth and showed that the term structure contains information about future real activity that is independent from information about current or future monetary policy. Haubrich and Dombrosky (1996) found that the yield spread is an excellent predictor of fourquarter economic growth but its predictive content has changed over time. Estrella and Mishkin (1997) confirmed that the basic results of Estrella and Hardouvelis (1991) continue to hold in a number of European countries as well as in the United States. Dueker (1997) has shown that the yield spread among leading indicators is a relatively good recession predictor. Estrella and Mishkin (1998) found the spread to be the best out-of-sample predictor of the probability of a 
recession occurring in the next four quarters. Dotsey (1998) has thoroughly investigated the forecasting properties of the yield spread for economic activity. He concluded that the spread contains useful information beyond that contained in past economic activity or past monetary policy, although over more recent periods the spread has not been nearly as informative as it has been in the past. Many other papers also have demonstrated the predictive power of the spread for future economic activity.

Why does the yield spread help forecast the business cycle? While a large literature provides evidence on the usefulness of the yield spread as a predictor of economic activity, few studies have addressed this question. In particular, even though several researchers have observed that the time-varying term premium is a significant component of the yield spread, no one has yet proposed a way of separately measuring the role of the term premium itself in accounting for the spread's usefulness in forecasting.

The paper begins with a review of the forecasting usefulness of the spread. We confirm and extend the conclusion of earlier studies that the yield spread between the 10 -year Treasury bond rate and the 3-month Treasury bill rate contains information about future real GDP beyond that contained in various measures of monetary policy or oil price changes. We then note that the empirical contribution of the yield spread for predicting economic activity can be decomposed into separate contributions of expected changes in interest rates and the term premium. Specifically, we attempt to answer the following question: given that the short rate rises relative to the long rate prior to a recession, to what extent is this because future short rates are rationally expected to fall (simple expectations hypothesis), and to what extent is it because the forecastable excess yield from holding long-term bonds (term premium) has fallen (which must be either a risk premium or a liquidity premium)? We find that both factors make statistically important contributions. The contributions are similar at short horizons but the effect of expected 
future short rates is much more important than the term premium for predicting GDP more than 2 years ahead.

We then go on to investigate why the term premium may be playing a useful role. We use a two-factor affine pricing model of the term structure based on Longstaff and Schwartz (1992) and Campbell, Lo, and MacKinlay (1997). In this model, two factors, which can be interpreted as the current level of the short rate and its volatility, determine the yield spread as well as expected changes in future short rates and the term premium. We find empirically that although interest rate volatility is a statistically significant factor in all three magnitudes, cyclical variation of interest rate volatility does not explain why any of the three magnitudes help predict economic activity.

\section{THE PREDICTIVE POWER OF THE SPREAD}

\subsection{The predictability of real economic activity using the yield spread}

Our study uses the 10-year T-bond rate, 3-month T-bill rate, and real GDP from 1953:Q2 to 1998:Q2. The source of interest rates is the Statistical Release H.15 of the Federal Reserve Board of Governors, while real GDP is taken from the DRI Economic Database (formerly Citibase Economic Database).

Figure 1 displays (1) the yield spread between the discount equivalent yield on the 10 -year Treasury bond and the 3-month Treasury bill and (2) the annualized rate of growth of real GDP over the next 4 quarters. The NBER recession dates are shaded in. On several occasions prior to historical recessions, short rates rose above prevailing long rates, a phenomenon known as an inverted yield curve. The figure illustrates episodes when the gap between two interest rates became negative. The yield curve has flattened or become inverted prior to all seven recessions. Many researchers have identified the extent to which the yield curve is tilted away from its 
normal slope as a useful leading indicator of recessions. Of course, the yield curve does not have to become inverted to signal that recession is imminent; it may simply flatten relative to normal.

Many previous studies, such as Estrella and Hardouvelis (1991), Estrella and Mishkin (1997), Haubrich and Dombrosky (1996), Bonser-Neal and Morley (1997), Kozicki (1997) and Dotsey (1998), used the following regression to examine the predictability of the yield spread for real activity:

$$
\begin{aligned}
& y_{t}^{k}=\alpha_{0}+\alpha_{1} \text { Spread }_{t}+\varepsilon_{t}, \\
& y_{t}^{k}=(400 / k) *\left(\ln Y_{t+k}-\ln Y_{t}\right), \\
& \text { Spread }_{t}=i_{t}^{n}-i_{t}^{1},
\end{aligned}
$$

where $Y_{t+k}$ is real GDP in quarter $t+k, y_{t}^{k}$ is the annualized real GDP growth over the next $k$ quarters, and $i_{t}^{n}, i_{t}^{1}$ are the 10-year Treasury bond rate and the 3-month Treasury bill rate at time $t$. Table 1 shows the results of the estimation of equation (2.1) using OLS. These estimates are qualitatively similar to those obtained by previous researchers, confirming that the yield spread helps predict real GDP growth up to 8 quarters ahead.

Although equation (2.1) follows most of the literature in trying to predict the cumulative GDP growth over the next $k$ quarters, it is also of interest as in Estrella and Hardouvelis (1991), Plosser and Rouwenhorst (1994), Kozicki(1997), and Dotsey (1998) to measure the marginal effect on year-to-year GDP growth for a horizon $k$ quarters in the future. Table 2 confirms that the spread makes a contribution to year-to-year growth rates for up to seven quarters in the future, though interestingly makes a negative contribution as one looks to a four-year horizon. 


\subsection{The role of other variables}

Following Haubrich and Dombrosky (1996), Bonser-Neal and Morley (1997), Kozicki (1997), and Dotsey (1998) we also estimated the following equation,

$y_{t}^{k}=\beta_{0}+\beta_{1}$ Spread $_{t}+\beta_{2} y_{t-1}^{1}+\beta_{3} y_{t-2}^{1}+\beta_{4} y_{t-3}^{1}+\beta_{5} y_{t-4}^{1}+\varepsilon_{t}$,

where $y_{t-i}^{1}$ is quarterly real GDP growth beginning in quarter $t-i$. Because current and lagged rates of growth of real GDP may be useful for forecasting future GDP, these real growth rates are included in the estimated equation (2.2).

Table 3 shows the estimation results for equation (2.2). Again these results are qualitatively similar to previous studies. The values of the estimated coefficient on the spread are slightly smaller than the estimated coefficients without including lagged real GDP growth, but remain statistically significant at conventional levels up to 8 quarters ahead. Thus, the yield spread

provides additional information beyond that contained in current and lagged growth rates. ${ }^{6}$ The statistical significance of the estimated coefficient on the spread shows a similar pattern with that of the estimated coefficient on the spread without lagged real GDP growth as explanatory variables.

Estrella and Hardouvelis (1991), Plosser and Rouwenhorst (1994), Estrella and Mishkin (1997), and Dotsey (1998) have investigated whether the yield spread has additional information beyond that contained in monetary policy. The following regression allows us to take a look at whether there is predictive power of the yield spread over and above that provided by other variables:

$y_{t}^{k}=\beta_{0}+\beta_{1}$ Spread $_{t}+\boldsymbol{\beta}^{\mathbf{\prime}} \mathbf{x}_{t}+\varepsilon_{t}$

where $\mathbf{x}_{t}$ is a vector of alternative explanatory variables. Following Plosser and Rouwenhorst (1994), and Estrella and Mishkin (1997), we used the Federal funds rate and two monetary aggregates as measures of monetary policy. The source of Federal funds rate and narrow (M1) 
and broad (M2) monetary aggregates is the Statistical Release H.15 and H.6 of the Federal Reserve Board of Governors! We also explored a possible role of oil prices, measured by both the quarterly logarithmic growth rate of the nominal crude oil producer price index and Hamilton's (1996) measure of the net oil price increase (defined as the amount by which oil prices in quarter $t$ exceed their peak value over the previous 4 quarters; if they do not exceed the previous peak, then the value is taken to be zero). Table 4 shows that even when all these variables are included together, the result remains that the yield spread helps to predict economic growth up to two years ahead. Similar results were obtained from bivariate regressions including additional lags.

\subsection{Why might the spread predict GDP growth?}

The yield spread is determined by the financial market's expectation of future short rates and a term premium. The relationship between the yield spread and future economic activity could be explained either in terms of the spread's role as a signal of the future expected short rates (the expectation effect) or as a signal of the change in the term premium (the term premium effect).

Suppose that the Fed adopts a contractionary monetary policy. In this case, market participants expect that tight monetary policy will temporarily raise short-term interest rates. If the current short-term interest is higher than the expected future short-term rate, this means that the long-term rate should rise less than the short-term rate according to the expectations hypothesis. Thus, the yield spread will be flattened. The monetary contraction will eventually also reduce spending in interest sensitive sectors of the economy, causing economic growth to slow. Conversely, easy monetary policy would result in a high yield spread, which would signal faster future real economic growth. According to this scenario, the positive correlation between 
the spread and future economic growth results from the expectations hypothesis of the term structure and the temporary influence of monetary policy.

Alternatively, market expectations of future economic growth may be reflected in the spread through the expected future change in the short-term rate. If market participants anticipate an economic boom and future higher rates of return to investment, then expected future short rates exceed the current short rate and the yield on long-term bonds should rise relative to short-term yields according to the expectations hypothesis. From the consumption side, Harvey (1988) observed that low expected values for the future marginal utility of consumption would also make the long rate higher relative to the short rate prior to an anticipated boom.

Both of these interpretations of the yield spread's usefulness for forecasting real output operate through the spread's role as a signal of future expected short rates. However, the spread also contains a term premium, which reflects in part the risk of alternative investments. For example, if interest rates become more volatile at the end of an expansion, this could reduce the spread, as will be seen in equation (3.12) below. Then long rates might fall relative to short rates at the end of an expansion, not because future short rates are expected to fall, but because the cyclical volatility warrants a change in the risk premium. Other cyclical factors in the term premium or liquidity premium could conceivably also account for the correlation.

To investigate these possibilities, it would be useful to be able to decompose the spread's forecasting contribution into an expectations effect and a term premium effect, to see which mechanism accounts for the historical correlation.

\subsection{A decomposition of why the yield spread helps forecast GDP}

As before, let $i_{t}^{n}, i_{t}^{1}$ denote the $n$-period interest rate (long-term rate) and one-period interest rate (short-term rate) respectively. Consider the following definition of the time-varying term premium $T P_{t}$ : 
$i_{t}^{n}=\frac{1}{n} \sum_{j=0}^{n-1} E_{t} i_{t+j}^{1}+T P_{t}$

where $E_{t}\left(i_{t+j}^{1}\right)$ denotes the market's expectation at time $t$ of the value of $i_{t+j}^{1}$. The term premium $T P_{t}$ could be viewed, for example, as the sum of a liquidity premium $\left(\eta_{t}\right)$ and risk premium $\left(\theta_{t}\right): T P_{t}=\eta_{t}+\theta_{t}$; see $\operatorname{Kim}(2000)$. Equation (2.5) can alternatively be written $i_{t}^{n}-i_{t}^{1}=\left(\frac{1}{n} \sum_{j=0}^{n-1} E_{t} i_{t+j}^{1}-i_{t}^{1}\right)+T P_{t}$

Equation (2.6) implies that the spread can be decomposed into two terms. The first term on the right-hand side of equation (2.6) is the difference between short-term interest rates expected over the next $n$ periods and the current rate. The second term is the time-varying term premium. Thus, if a fall in the spread predicts U.S. recessions, it could either be because (1) a temporarily high short-term rate suggests a coming recession, or (2) a fall in the premium on long-term bonds relative to short-term bonds suggests an economic recession. Given that the short rate rises relative to the long rate prior to a recession, to what extent is this because future short rates are rationally expected to fall (the simple expectations hypothesis), and to what extent is it because the forecastable excess yield from holding long-term bonds has fallen (which must be a risk premium or a liquidity premium)? We now show how this question can be answered from the data.

Notice that the spread can be written

$i_{t}^{n}-i_{t}^{1}=\left(\frac{1}{n} \sum_{j=0}^{n-1} E_{t} i_{t+j}^{1}-i_{t}^{1}\right)+\left(i_{t}^{n}-\frac{1}{n} \sum_{j=0}^{n-1} E_{t} i_{t+j}^{1}\right)$.

Substituting equation (2.7) into (2.1),

$y_{t}^{k}=\alpha_{0}+\alpha_{1}\left(\frac{1}{n} \sum_{j=0}^{n-1} E_{t} i_{t+j}^{1}-i_{t}^{1}\right)+\alpha_{1}\left(i_{t}^{n}-\frac{1}{n} \sum_{j=0}^{n-1} E_{t} i_{t+j}^{1}\right)+\varepsilon_{t}$. 
Expression (2.8) decomposes the contribution of the spread into the effect of expected future changes in short rates $\left(\frac{1}{n} \sum_{j=0}^{n-1} E_{t} i_{t+j}^{1}-i_{t}^{1}\right)$ and the effect of the term premium $\left(T P_{t}=i_{t}^{n}-\frac{1}{n} \sum_{j=0}^{n-1} E_{t} i_{t+j}^{1}\right)$. A generalization of equation (2.8) would allow these two components to have different implications for future GDP:

$$
y_{t}^{k}=\gamma_{0}+\gamma_{1}\left(\frac{1}{n} \sum_{j=0}^{n-1} E_{t} i_{t+j}^{1}-i_{t}^{1}\right)+\gamma_{2}\left(i_{t}^{n}-\frac{1}{n} \sum_{j=0}^{n-1} E_{t} i_{t+j}^{1}\right)+e_{t}
$$

Let $v_{t+n}$ denote the error in forecasting future short-term rates:

$v_{t+n}=\frac{1}{n} \sum_{j=0}^{n-1} i_{t+j}^{1}-\frac{1}{n} \sum_{j=0}^{n-1} E_{t} i_{t+j}^{1}$.

Then (2.9) can be written

$$
y_{t}^{k}=\gamma_{0}+\gamma_{1}\left(\frac{1}{n} \sum_{j=0}^{n-1} i_{t+j}^{1}-i_{t}^{1}\right)+\gamma_{2}\left(i_{t}^{n}-\frac{1}{n} \sum_{j=0}^{n-1} i_{t+j}^{1}\right)+u_{t}
$$

where $u_{t}=e_{t}+\left(\gamma_{2}-\gamma_{1}\right) v_{t+n}$. Under rational expectations, the error term $u_{t}$ should be uncorrelated with any variable known at time $t$. Thus, (2.10) can be estimated using instrumental variable estimation with any variables dated $t$ or earlier as instruments.

Table 5 shows the estimation results for equation (2.10), with a constant, $i_{t}^{n}$, and $i_{t}^{1}$ as instruments; similar results were obtained when all the variables in Table 4 were used as instruments. The estimated coefficient on the future expected short-term interest rate change over $n$ periods is statistically significant up to 12 quarters ahead at the $1 \%$ level and the coefficient on the term premium is statistically significant at the $1 \%$ level up to 8 quarters ahead. Thus, both the expected change of the short-term rate over $n$ periods (the simple expectations hypothesis) and the time-varying term premium help predict real GDP growth up to 8 quarters ahead. Which factor contributes more to predicting real GDP growth? The results of a Wald test of the null 
hypothesis that the coefficient on the expected change of short-term rates over $n$ periods is equal to that of the term premium are shown in the fifth column of Table 5. Even though the estimated coefficients are similar, the null hypothesis is rejected in all cases where both estimated coefficients are statistically significant. The contribution of the future expected change of shortterm rates to prediction of real GDP growth is statistically significantly bigger than that of the term premium. Hence the most important reason that a negative yield spread predicts slower real GDP growth is that a low spread implies falling future short-term interest rates.

One factor that should matter for the term premium is the volatility of interest rates. The following section develops a theoretical model for investigating the effect of interest rate volatility on the term structure to see whether cyclical variation in volatility could account for the predictive ability of the spread and term premium.

\section{THE ROLE OF INTEREST RATE VARIABILITY AND THE RISK PREMIUM}

\subsection{A two-factor affine model of the term structure}

To understand why the term premium might help predict the level of economic activity, we investigate a simple model of the term structure. Following Campbell, Lo and MacKinlay (1997, p. 428), let $P_{t}^{n}$ denote the price of an $n$-period discount bond purchased at $t$ whose redemption value at $t+n$ is unity, and let $M_{t}$ denote a pricing kernel satisfying

$$
P_{t}^{n}=E_{t}\left(P_{t+1}^{n-1} M_{t+1}\right)
$$

For example, one popular specification uses $M_{t+1}=\beta U^{\prime}\left(C_{t+1}\right) / U^{\prime}\left(C_{t}\right)$. If we assume that $\left(P_{t+1}^{n-1}, M_{t+1}\right)^{\prime}$ is jointly conditionally lognormal, then taking logs of (3.1) results in

$$
p_{t}^{n}=E_{t}\left(p_{t+1}^{n-1}+m_{t+1}\right)+(1 / 2) \operatorname{Var}_{t}\left(p_{t+1}^{n-1}+m_{t+1}\right)
$$

where lowercase letters denote logarithms. Note that (3.2) implies that an increase in the variability of either future bond prices or the pricing kernel results in a higher price of an $n$ - 
period bond relative to expected future values for $m_{t+1}$ and $p_{t+1}^{n-1}$. Hence, if the end of an economic expansion is characterized by an increase in the variability of either interest rates or the pricing kernel, then this might appear as a drop in the yield on long-term bonds relative to shortterm bonds.

We investigate this possibility in more detail using the two-factor affine yield model of Longstaff and Schwartz (1992) as discretized by Campbell, Lo and MacKinlay (1997, pp. 438439). Suppose that the log of the pricing kernel can be described with two factors, $x_{1 t}$ and $x_{2 t}$, $-m_{t+1}=x_{1 t}+x_{2 t}+x_{1 t}^{1 / 2} \beta \xi_{1, t+1}$

where the factors evolve according to

$$
\begin{aligned}
& x_{1, t+1}=\left(1-\phi_{1}\right) \mu_{1}+\phi_{1} x_{1 t}+x_{1 t}^{1 / 2} \xi_{1, t+1} \\
& x_{2, t+1}=\left(1-\phi_{2}\right) \mu_{2}+\phi_{2} x_{2 t}+x_{2 t}^{1 / 2} \xi_{2, t+1} .
\end{aligned}
$$

Note both factors are heteroskedastic, displaying the greatest variance when the level is highest, and innovations in factor 1 are perfectly correlated with the pricing kernel. The innovations $\left(\xi_{1, t}, \xi_{2 t}\right)^{\prime}$ are independent Gaussian white noise with variances $\sigma_{1}^{2}$ and $\sigma_{2}^{2}$ respectively. Setting $n=1$ and noting that the one-period bond yield $i_{t}^{1}$ corresponds to $-p_{t}^{1}$, we deduce from (3.2) and (3.3) that

$i_{t}^{1}=\left(1-\beta^{2} \sigma_{1}^{2} / 2\right) x_{1 t}+x_{2 t}$.

Using (3.4) and (3.5), it follows from (3.6) that

$\operatorname{Var}_{t}\left(i_{t+1}^{1}\right)=\left(1-\beta^{2} \sigma_{1}^{2} / 2\right)^{2} \sigma_{1}^{2} x_{1 t}+\sigma_{2}^{2} x_{2 t}$

Equations (3.6) and (3.7) can be used to solve for $x_{1 t}$ and $x_{2 t}$ in terms of $i_{t}^{1}$ and $\operatorname{Var}_{t}\left(i_{t+1}^{1}\right)$; hence the level and conditional variance of the short-term interest rate can be used to represent the two factors that will determine any yield in this framework. It is mathematically simpler to 
represent the factors as $x_{1 t}$ and $x_{2 t}$, noting that, provided we assume that $\left(1-\beta^{2} \sigma_{1}^{2} / 2\right)>0$, an increase in either $x_{1 t}$ or $x_{2 t}$ results in both an increase in the level of the short-term rate and an increase in its conditional variance.

In general, Campbell, Lo and MacKinlay show that the log price of an $n$-period bond can be characterized by

$$
\begin{aligned}
& -p_{t}^{n}=A_{n}+B_{1 n} x_{1 t}+B_{2 n} x_{2 t} \\
& B_{1 n}=1+\phi_{1} B_{1, n-1}-\left(\beta+B_{1, n-1}\right)^{2} \sigma_{1}^{2} / 2 \\
& B_{2 n}=1+\phi_{2} B_{2, n-1}-B_{2, n-1}^{2} \sigma_{2}^{2} / 2 \\
& A_{n}-A_{n-1}=\left(1-\phi_{1}\right) \mu_{1} B_{1, n-1}+\left(1-\phi_{2}\right) \mu_{2} B_{2, n-1}
\end{aligned}
$$

where, from (3.6), $A_{1}=0, B_{11}=\left(1-\beta^{2} \sigma_{1}^{2} / 2\right)$ and $B_{21}=1$. The spread can be calculated as

$$
\begin{aligned}
i_{t}^{n}-i_{t}^{1}= & -n^{-1} p_{t}^{n}-i_{t}^{1} \\
& =n^{-1} A_{n}+\left(n^{-1} B_{1 n}-B_{11}\right) x_{1 t}+\left(n^{-1} B_{2 n}-B_{21}\right) x_{2 t} .
\end{aligned}
$$

Note that since $\phi_{i}<1$ and $B_{i n}<\left(1+\phi_{i}+\phi_{i}^{2}+\ldots+\phi_{i}^{n-1}\right) B_{i 1}$, it follows that $n^{-1} B_{i n}-B_{i 1}<0$. Hence an increase in either factor will produce a decrease in the spread.

To calculate the effect on the term premium, notice that

$$
\sum_{j=0}^{n-1} E_{t} x_{i, t+j}=C_{i n}+D_{i n} x_{i t}
$$

where the coefficients $C_{i n}$ and $D_{i n}$ can be deduced recursively from the fact that

$$
\sum_{j=0}^{n-1} E_{t} x_{i, t+j}=x_{i t}+E_{t}\left(\sum_{j=0}^{n-2} E_{t+1} x_{i, t+j+1}\right)
$$

so that

$$
C_{i n}+D_{i n} x_{i t}=x_{i t}+E_{t}\left(C_{i, n-1}+D_{i, n-1} x_{i, t+1}\right)
$$




$$
D_{i n}=1+\phi_{i} D_{i, n-1}
$$

It follows from (3.13) and (3.6) that

$\sum_{j=0}^{n-1} E_{t} i_{t+j}^{1}=B_{11}\left(C_{1 n}+D_{1 n} x_{1 t}\right)+B_{21}\left(C_{2 n}+D_{2 n} x_{2 t}\right)$

where $B_{11}=\left(1-\beta^{2} \sigma_{1}^{2} / 2\right)$ and $B_{21}=1$.

From (3.17) and (3.6) one can calculate the expected change in interest rates as

$n^{-1} \sum_{j=0}^{n-1} E_{t} i_{t+j}^{1}-i_{t}^{1}=A_{n}^{e}+B_{1 n}^{e} x_{1 t}+B_{2 n}^{e} x_{2 t}$

where $B_{i n}^{e}=B_{i 1}\left(n^{-1} D_{i n}-1\right)<0$. Likewise the term premium can be characterized by

$i_{t}^{n}-n^{-1} \sum_{j=0}^{n-1} E_{t} i_{t+j}^{1}=A_{n}^{p}+B_{1 n}^{p} x_{1 t}+B_{2 n}^{p} x_{2 t}$

where $B_{i n}^{p}=n^{-1}\left(B_{i n}-B_{i 1} D_{i n}\right)$. Note that $B_{i 1}^{p}=B_{i 1}\left(1-D_{i 1}\right)=0$ since $D_{i 1}=1$. Furthermore,

(3.9) and (3.16) establish that

$$
\begin{aligned}
B_{1 n}^{p}-\phi_{1} B_{1, n-1}^{p} & =n^{-1}\left[B_{1 n}-\phi_{1} B_{1, n-1}-B_{11}\left(D_{1 n}-\phi_{1} D_{1, n-1}\right)\right] \\
& =n^{-1}\left[1-\left(\beta+B_{1, n-1}\right)^{2} \sigma_{1}^{2} / 2-B_{11}\right] \\
& =n^{-1}\left[\beta^{2} \sigma_{1}^{2} / 2-\left(\beta+B_{1, n-1}\right)^{2} \sigma_{1}^{2} / 2\right]
\end{aligned}
$$

which for typical parameter values should be negative for all $n$. Likewise

$$
\begin{aligned}
B_{2 n}^{p}-\phi_{2} B_{2, n-1}^{p} & =n^{-1}\left[1-B_{2, n-1}^{2} \sigma_{2}^{2} / 2-B_{21}\right] \\
& =-n^{-1} B_{2, n-1}^{2} \sigma_{2}^{2} / 2 \\
& <0 .
\end{aligned}
$$

Equations (3.12), (3.18), and (3.19) establish that the spread, expected change in interest rates, and term premium all take the form $y_{n t}=A_{n}^{y}+B_{1 n}^{y} x_{1 t}+B_{2 n}^{y} x_{2 t}$ for $y_{n t}=i_{t}^{n}-i_{t}^{1}, n^{-1} \sum_{j=0}^{n-1} E_{t} i_{t+j}^{1}-i_{t}^{1}$, or $i_{t}^{n}-n^{-1} \sum_{j=0}^{n-1} E_{t} i_{t+j}^{1}$, with $B_{i n}^{y}<0$. Note further from (3.7) and the independence of the factors $x_{1 t}$ and $x_{2 t}$ that the covariance between $y_{n t}$ and $\operatorname{Var}_{t}\left(i_{t+1}^{1}\right)$ is 
given by $B_{1 n}^{y} B_{11}^{2} \sigma_{1}^{2} \operatorname{Var}\left(x_{1 t}\right)+B_{2 n}^{y} \sigma_{2}^{2} \operatorname{Var}\left(x_{2 t}\right)<0$. Since the ex-post magnitudes differ from the expected values by a term that is uncorrelated with information available at time $t$, it follows that a regression of any of these three ex-post magnitudes on the conditional variance at time $t$ should yield a negative coefficient.

\subsection{Empirical results}

To investigate the empirical relevance of changes over time in the variance of interest rates, we examined two alternative descriptions of time variation in the volatility of interest rates. Our first measure is based on the GARCH-type model of Brenner, Harjes, and Kroner (1996) which treats volatility as a function of both the interest rate level and previous squared interest rate innovations:

$i_{t}^{1}=c+\phi i_{t-1}^{1}+\varepsilon_{t}$

$\varepsilon_{t} \mid \Omega_{t-1} \sim N\left(0, \sigma_{t \mid t-1}^{2}\right)$

$\sigma_{t \mid t-1}^{2}-\omega=\alpha\left(\varepsilon_{t-1}^{2}-\omega\right)+\beta\left(\sigma_{t-1 \mid t-2}^{2}-\omega\right)+\gamma\left(i_{t-1}^{1}-2\right)$

where we started the recursion for $\sigma_{t \mid t-1}^{2}$ by setting $\varepsilon_{0}^{2}=\sigma_{0 \mid-1}^{2}=\omega$. Maximum likelihood estimates are as follows, with conventional standard errors in parentheses:

$$
\begin{aligned}
& i_{t}^{1}=\underset{(0.190}{0}+0.964 i_{t-1}^{1}+\varepsilon_{t} \\
& (0.019) \\
& \sigma_{t \mid t-1}^{2}=\underset{(0.045)}{0.077}+\underset{(0.13)}{0.32}\left(\varepsilon_{t-1}^{2}-0.077\right)+\underset{(0.15)}{0.48}\left(\sigma_{t \mid t-1}^{2}-0.077\right)+\underset{(0.0117)}{0.0257}\left(i_{t-1}^{1}-2\right) .
\end{aligned}
$$

We then used the fitted values $\hat{\sigma}_{t+1 \mid t}^{2}$ in regressions explaining the spread, ex post change in interest rates, and ex post term premium at date $t$ (for $n=40$ quarters and $i_{t}^{n}$ the 10 -year bond yield) obtaining the following empirical estimates (heteroskedasticity and 12-lag autocorrelation consistent standard errors in parentheses): ${ }^{9}$ 


$$
\begin{aligned}
& i_{t}^{n}-i_{t}^{1}=\underset{(0.21)}{1.44-0.27} \hat{\sigma}_{t+1 \mid t}^{2}+u_{t} \\
& n^{-1} \sum_{j=0}^{n-1} E_{t} i_{t+j}^{1}-i_{t}^{1}=\underset{(0.42)}{1.21-1.28} \hat{\sigma}_{t+1 \mid t}^{2}+u_{t} \\
& i_{t}^{n}-n^{-1} \sum_{j=0}^{n-1} E_{t} i_{t+j}^{1}=\underset{(0.19)}{0.10+1.06} \hat{\sigma}_{t+1 \mid t}^{2}+u_{t} .
\end{aligned}
$$

Our second measure of interest rate volatility is a version of the "realized volatility" that has been employed by several researchers and rigorously defended by Andersen, et. al. (2000). Specifically, we construct $\widetilde{\sigma}_{t+1 \mid t}^{2}$ from the variance of the level of daily three-month Treasury bill rates during quarter $t$; prior to $1962: \mathrm{Q} 2$, we use the variance of weekly three-month rates. ${ }^{10} \mathrm{We}$ then estimated the following by OLS over 1954:Q1 to 1998:Q2:

$$
\begin{aligned}
& i_{t}^{n}-i_{t}^{1}=1.36-0.23 \widetilde{\sigma}_{t+1 \mid t}^{2}+u_{t} \\
& \text { (0.21) (0.09) } \\
& n^{-1} \sum_{j=0}^{n-1} E_{t} i_{t+j}^{1}-i_{t}^{1}=\underset{(0.52)}{0.72-0.96} \widetilde{\sigma}_{t+1 \mid t}^{2}+u_{t} \\
& i_{t}^{n}-n^{-1} \sum_{j=0}^{n-1} E_{t} i_{t+j}^{1}=0.51+0.76 \widetilde{\sigma}_{t+1 \mid t}^{2}+u_{t} .
\end{aligned}
$$

The two measures produce very similar results. Higher interest rate volatility is associated with a decrease in the spread and an expected drop in interest rates, as predicted in equations (3.12) and (3.18). However, higher volatility appears in (3.23) and (3.26) to increase the term premium, rather than decrease as predicted by equation (3.19). Nevertheless, volatility is seen to play an important empirical role in all three magnitudes, and is clearly something that a priori should affect the term structure of interest rates, even if that effect in reality is more 
complicated than is captured by the simple theoretical model in (3.2) through (3.5). It accordingly seems worth investigating whether the ability of the spread and the term premium to predict future downturns in GDP growth might be accounted for by the fact that interest rate volatility is perceived to be higher at the end of an expansion.

To investigate this possibility, we added interest rate volatility to the specification in $(2.10)$ $y_{t}^{k}=\gamma_{0}+\gamma_{1}\left(\frac{1}{n} \sum_{j=0}^{n-1} i_{t+j}^{1}-i_{t}^{1}\right)+\gamma_{2}\left(i_{t}^{n}-\frac{1}{n} \sum_{j=0}^{n-1} i_{t+j}^{1}\right)+\gamma_{3} \hat{\sigma}_{t+1 \mid t}^{2}+u_{t}$

which is now estimated by instrumental variables with instruments $i_{t}^{1}, i_{t}^{n}, \hat{\sigma}_{t+1 \mid t}^{2}$, and a

constant. ${ }^{11}$ Results are presented in Table 6; very similar results were found for $\widetilde{\sigma}_{t+1 \mid t}^{2}$. Although $\hat{\sigma}_{t+1 \mid t}^{2}$ or $\widetilde{\sigma}_{t+1 \mid t}^{2}$ makes a statistically significant contribution to predicting GDP growth at horizons of two to four quarters, the coefficient is positive (higher volatility precedes faster GDP growth), and thus could not account for the positive coefficient relating the yield spread to GDP (a higher yield spread precedes faster GDP growth), given that high volatility is associated with a low yield spread. Furthermore, the coefficients $\hat{\gamma}_{1}$ and $\hat{\gamma}_{2}$ both become even bigger in magnitude once $\hat{\sigma}_{t+1 \mid t}^{2}$ has been added to the regression, meaning that the omission of $\hat{\sigma}_{t+1 \mid t}^{2}$ from (2.10) was not determining those results. We thus conclude that although interest rate volatility is an important determinant of the term structure of interest rates and an a priori plausible explanation for why the term premium helps predict GDP growth, in practice it appears that the explanation for why the interest spread helps forecast economic activity must be sought elsewhere.

\section{CONCLUSION}

We have confirmed earlier results on the usefulness of the spread between long-term and short-term interest rates for forecasting GDP growth. We have shown how to decompose this 
effect into an expectations effect and a term premium effect. Both effects are statistically significant $-a$ forecast of falling short-term interest rates is associated with a forecast of slower GDP growth, and an increase in the expected return from rolling over 1-period bonds relative to an $n$-period bond is also associated with a forecast of slower GDP growth— though the first effect (the expectations effect) is slightly more important quantitatively and statistically.

We proposed a simple model for interpreting the second effect (the term premium effect) based on time-variation in the variance of short-term interest rates. According to the model, an increase in interest rate volatility at the end of an expansion could explain why the spread and term premium fall at the end of the expansion. We found that volatility is an empirically important determinant of the spread and the term premium and a useful predictor of future interest rates. However, cyclical movements in volatility appear to be unable to account for the usefulness of the spread and term premium for forecasting GDP. 


\section{References}

Abken, Peter A. "Inflation and the Yield Curve." Federal Reserve Bank of Atlanta Economic Review 78 (1993), 13-31.

Andersen, Torben G., Tim Bollerslev, Francis X. Diebold, and Paul Labys. "The Distribution of Realized Exchange Rate Volatility.” Journal of the American Statistical Association (2000), forthcoming.

Atta-Mensah, Joseph and Greg Tkacz. "Predicting Canadian Recessions Using Financial Variables: A Probit Approach.” Canadian Business Economics (2001), forthcoming.

Benninga, Simon and Aris Protopapadakis. "Real and Nominal Interest Rates under Uncertainty: The Fisher Theorem and the Term Structure." Journal of Political Economy 91 (1983), 856-867.

Bernanke, Ben S. "On the Predictive Power of Interest Rates and Interest Rate Spreads." Federal Reserve Bank of Boston New England Economic Review, (November/December 1990), $51-68$.

Bernard, Henri, and Stefan Gerlach. "Does the Term Structure Predict Recessions? The International Evidence.” International Journal of Finance and Economics 3 (1998), 195-215.

Bollerslev, Tim, R. C. Chou, and Kenneth Kroner. "ARCH Modeling in Finance: A Review of the Theory and Empirical Evidence.” Journal of Econometrics 52 (1992), 5-59.

Bollerslev, Tim, Robert F. Engle, and Daniel B. Nelson. "ARCH Models.” In Handbook of Econometrics, Vol. 4, edited by Robert F. Engle and Daniel L. McFadden. Amsterdam: NorthHolland, 1994.

Bonser-Neal, Catherine, and Timothy R. Morley. "Does the Yield Spread Predict Real Economic Activity? A Multicountry Analysis." Federal Reserve Bank of Kansas City Economic Review, (Third Quarter 1997), 37-53. 
Brenner, Robin J., Richard H. Harjes, and Kenneth F. Kroner. “Another Look at Models of the Short-Term Interest Rate.” Journal of Financial and Quantitative Analysis 31 (1996), 85-107.

Campbell, John Y., Andrew W. Lo, and A. Craig MacKinlay. The Econometrics of Financial Markets. Princeton: Princeton University Press, 1997.

Chen, Ren-Raw and Louis Scott. "Maximum Likelihood Estimation for a Multifactor Equilibrium Model of the Term Structure of Interest Rates." Journal of Fixed Income 3 (December,1993), 14-31.

Davis, E. Philip and Gabriel Fagan. "Are Financial Spreads Useful Indicators of Future Inflation and Output Growth in EU Countries?” Journal of Applied Econometrics 12 (1997), 701714.

Davis, E. Philip and S. G. B. Henry. "The Use of Financial Spreads as Indicator Variables: Evidence for the United Kingdom and Germany.” IMF Staff Papers 41 (1994), 517-25.

Dotsey, Michael. "The Predictive Content of the Interest Rate Term Spread for Future Economic Growth.” Federal Reserve Bank of Richmond Economic Quarterly 84 (Summer 1998), $31-51$.

Dueker, Michael J. "Strengthening the Case for the Yield Curve as a Predictor of U.S. Recessions.” Federal Reserve Bank of St. Louis Review 79 (March/April 1997), 41-51.

Estrella, Arturo, and Gikas A. Hardouvelis. "The Term Structure as a Predictor of Real Economic Activity.” Journal of Finance 46 (1991), 555-576.

Estrella, Arturo, and Frederic S. Mishkin. "The Predictive Power of the Term Structure of Interest Rates in Europe and the United States: Implications for the European Central Bank." European Economic Review 41 (1997), 1375-1401.

Estrella, Arturo, and Frederic S. Mishkin. "Predicting U.S. Recessions: Financial Variables as Leading Indicators." Review of Economics and Statistics 80 (1998), 45-61. 
Fama, Eugene F. "Term-Structure Forecasts of Interest Rates, Inflation, and Real Returns." Journal of Monetary Economics 25 (1990), 59-76.

Frankel, Jeffrey A., and Cara S. Lown. "An Indicator of Future Inflation Extracted from the Steepness of the Interest Rate Yield Curve Along its Entire Length." Quarterly Journal of Economics 109 (1994), 517-530.

Friedman, Benjamin M., and Kenneth N. Kuttner. "Why Does the Paper-Bill Spread Predict Real Economic Activity?" In Business Cycles, Indicators, and Forecasting, edited by James Stock and Mark W. Watson. Chicago: University of Chicago Press, 1993.

Gerlach, Stefan. "The Information Content of the Term Structure: Evidence for Germany." Empirical Economics 22 (1997), 161-179.

Gong, Fangxiong, and Eli M. Remolona. "Two Factors along the Yield Curve.” Manchester School of Economic and Social Studies, Supplement 65 (1997), 1-31.

Hamilton, James D. "Oil and the Macroeconomy Since World War II." Journal of Political Economy 91 (1983), 228-248.

Hamilton, James D. "This is What Happened to the Oil Price-Macroeconomy Relationship." Journal of Monetary Economics 38 (1996), 215-220.

Hamilton, James D. “What is an Oil Shock?” NBER Working Paper 7755 (June 2000).

Harvey, Campbell R. "The Real Term Structure and Consumption Growth." Journal of Financial Economics 22 (1988), 305-333.

Harvey, Campbell R. "Forecasts of Economic Growth from the Bond and Stock Markets." Financial Analysts Journal 45 (September/October 1989), 38-45.

Harvey, Campbell R. "The Term Structure and World Economic Growth," Journal of Fixed Income 1 (1991a), 4-17.

Harvey, Campbell R. "Interest Rate Based Forecasts of German Economic Growth," Weltwirtschaftliches Archiv 127 (1991b), 701-718. 
Haubrich, Joseph G., and Ann M. Dombrosky. "Predicting Real Growth Using the Yield Curve." Federal Reserve Bank of Cleveland Economic Review 32 (First Quarter 1996), 26-35.

Hu, Zuliu. "The Yield Curve and Real Activity.” IMF Staff Papers 40 (1993), 781-806.

Jorion, Philippe, and Frederic Mishkin. "A Multicountry Comparison of Term-Structure Forecasts at Long Horizons.” Journal of Financial Economics 29 (1991), 59-80.

Kim, Dong Heon. "Another Look at the Yield Spread: Liquidity and the Term Structure of Interest Rates.” Ph.D. Dissertation (Chapter 1), University of California, San Diego, 2000.

Kozicki, Sharon. "Predicting Real Growth and Inflation with the Yield Spread." Federal Reserve Bank of Kansas City Economic Review 82 (Fourth Quarter 1997), 39-57.

Longstaff, Francis A., and Eduardo S. Schwartz. "Interest Rate Volatility and the Term Structure: A Two-Factor General Equilibrium Model. " Journal of Finance 47 (September 1992), 1259-1282.

Mishkin, Frederic. "What Does the Term Structure Tell Us about Future Inflation?” Journal of Monetary Economics 25 (1990), 77-95.

Mishkin, Frederic. "A Multi-Country Study of the Information in the Shorter Maturity Term Structure About Future Inflation.” Journal of International Money and Finance 10 (1991), 2-22.

Newey, Whitney K., and Kenneth D. West. "A Simple, Positive Semi-Definite, Heteroskedasticity and Autocorrelation Consistent Covariance Matrix.” Econometrica 55 (1987), 703-708.

Plosser, Charles I., and K. Geert Rouwenhorst. "International Term Structures and Real Economic Growth.” Journal of Monetary Economics 33 (1994), 133-155.

Sarte, Pierre-Daniel G. "Fisher's Equation and the Inflation Risk Premium in a Simple Endowment Economy.” Federal Reserve Bank of Richmond Economic Quarterly 84 (1998), 5372. 
Smets, Frank and Kostas Tsatsaronis. "Why Does the Yield Curve Predict Economic Activity? Dissecting the Evidence for Germany and the United States.” BIS Working Papers, No. 49, September 1997.

Stock, James H. and Mark W. Watson. "New Indexes of Coincident and Leading Indicators." In NBER Macroeconomic Annual, Vol. 4, edited by Olivier Blanchard and Stanley Fischer. Cambridge, MA: MIT Press, 1989.

Stock, James H. and Mark W. Watson. "Business Cycle Fluctuations in U.S. Macroeconomic Time Series.” In Handbook of Macroeconomics, Vol. IA, edited by John B. Taylor and Michael Woodford. Amsterdam: North-Holland, 1999. 


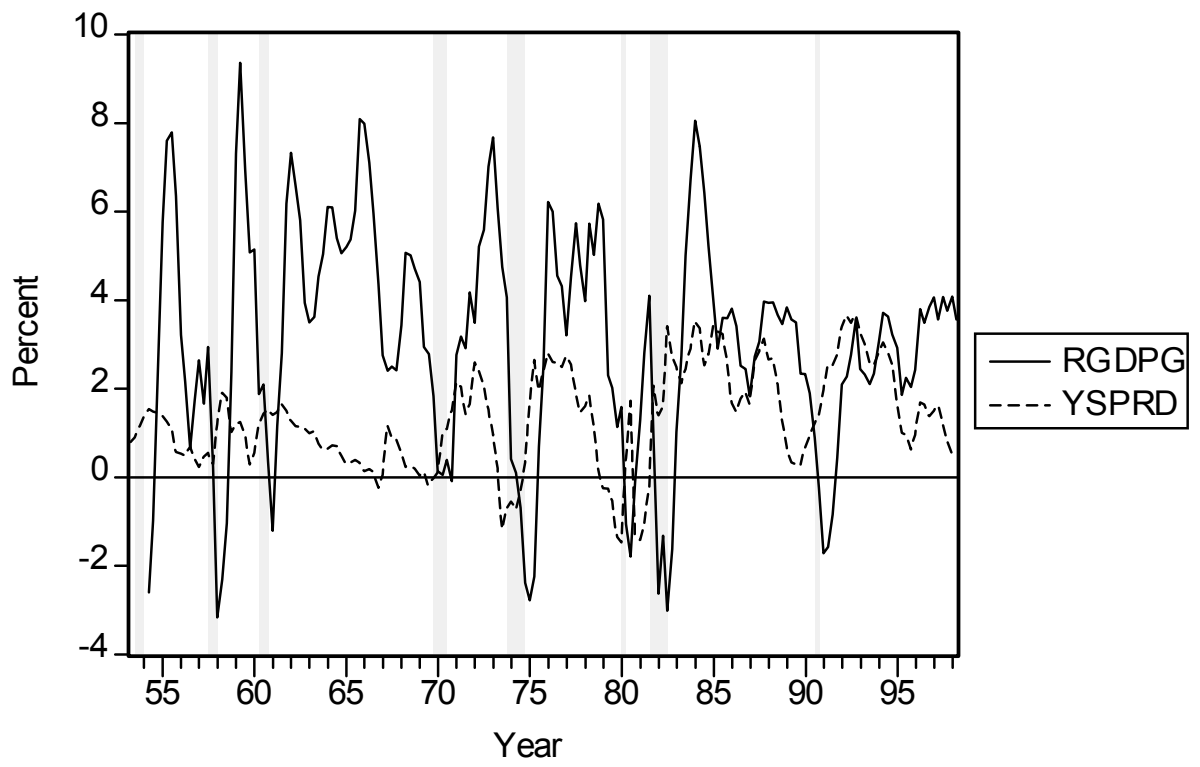

FIG. 1. The Four-quarter Growth Rate ofReal GDPand the Yield Spread. RGDPG=Four-quater Real GDP Growth Rate, YSPRD=Spread between 10-year T-bond rate and 3-month T-bill rate. The shaded areas are NBER recession dates. 


\section{Footnotes}

*This paper is based on Dong Heon Kim's Ph.D. dissertation (Chapter 2) at the University of California, San Diego. The research was supported by NSF Grant SES-0076072. We thank Paul Evans, Marjorie Flavin, Wouter Den Haan, Valerie Ramey, Eric Swanson, two anonymous referees, and seminar participants on UCSD macroeconomics workshop for helpful comments. All data used in this study can be downloaded from http://econ.ucsd.edu/ jhamilto.

${ }^{1}$ See for example Bernanke (1990), Friedman and Kuttner (1993), and Stock and Watson (1999).

2 These papers include Harvey (1991a,b), Hu (1993), Davis and Henry (1994), Bernard and Gerlach (1998), Davis and Fagan (1997), Bonser-Neal and Morley (1997), Kozicki (1997), Smets and Tsatsaronis (1997), and Atta-Mensah and Tkacz (2001), among others. Several studies, including Fama (1990), Mishkin (1990 and 1991), Jorion and Mishkin (1991), Abken (1993), Frankel and Lown (1994), Gerlach (1997), and Kozicki (1997), have further reported that the yield spread helps predict inflation at moderate to long horizons.

${ }^{3}$ See Kim (2000) for discussion of the time-varying term premium in the term structure of interest rates.

${ }^{4}$ For other theoretical models of the role of interest rate volatility, see Benninga and Protopapadakis (1983) and Sarte (1998).

${ }^{5}$ The monthly average interest rate series were converted to quarterly by averaging.

${ }^{6}$ Dotsey (1998) shows that the information content of the spread differs across sample periods and the spread does not appear to be statistically significant over some subperiods. Smets and Tsatsaronis (1997) also state that the predictive content of the term spread is not time-invariant.

${ }^{7}$ The monthly average Federal funds rate series and monthly monetary aggregate were converted to quarterly by averaging. Data for Federal funds rates are from July 1954 to June 1998 and data for the monetary aggregates are available from January 1959 to June 1998. 
${ }^{8}$ Subtraction of $\omega$ and 2 is simply a renormalization of the constant term, adopted for purposes of conveniently setting initial values appropriate for the beginning of the sample.

${ }^{9}$ We made no correction to the standard errors for the fact that $\hat{\sigma}_{t+1 \mid t}^{2}$ is a generated regressor; note that the generated regressor issue does not arise with our second measure. Note further that according to the theoretical model, the difference between the coefficients in (3.21) and (3.22) should equal the coefficients in (3.23). The empirical results do not satisfy this restriction exactly, because a regression of $y_{1 t}-y_{2 t}$ on $\mathbf{x}_{t}$ is not numerically equal to the difference between a regression of $y_{1 t}$ on $\mathbf{x}_{t}$ and $y_{2 t}$ on $\mathbf{x}_{t}$.

${ }^{10}$ Data are daily averages from the secondary market, quoted on a discount basis, downloaded from the St. Louis Fed database (http://www.stls.frb.org/fred/) on 1/17/01.

${ }^{11}$ Note that if the affine model were literally correct, the linear projection of the three right-hand variables in (3.27) on information available at date $t$ would be linearly dependent, since, according to the model, two factors alone entirely describe the entire term structure and expectations of all future interest rates. Our estimation of (3.27) thus implicitly assumes that more than these two factors alone matter for interest rates, and we use it to gauge the importance of the volatility factor relative to others. That any $K$-factor model does not literally describe the data is immediately established from the fact that any observed collection of interest rates of $(K+1)$ maturities are not perfectly linearly dependent. For empirical evidence that more than two factors are needed even for a looser interpretation of the framework, see Chen and Scott (1993) and Gong and Remolona (1997).

${ }^{11}$ Data are daily averages from the secondary market, quoted on a discount basis, downloaded from the St. Louis Fed database (http://www.stls.frb.org/fred/) on 1/17/01. 
Table 1. Predicting future real GDP growth using the yield spread

$$
y_{t}^{k}=\alpha_{0}+\alpha_{1} \text { Spread }_{t}+\varepsilon_{t}
$$

\begin{tabular}{|c|c|c|c|}
\hline$k$ (quarters ahead) & $\hat{\alpha}_{0}$ & $\hat{\alpha}_{1}$ & $\bar{R}^{2}$ \\
\hline \multirow[t]{2}{*}{1} & $1.818^{* * *}$ & $0.940^{* * *}$ & 0.066 \\
\hline & $(0.626)$ & $(0.342)$ & \\
\hline \multirow[t]{2}{*}{2} & $1.714^{* * *}$ & $1.029^{* * *}$ & 0.123 \\
\hline & $(0.631)$ & $(0.349)$ & \\
\hline \multirow[t]{2}{*}{3} & $1.753^{* * *}$ & $1.011^{* * *}$ & 0.156 \\
\hline & $(0.605)$ & $(0.336)$ & \\
\hline \multirow[t]{2}{*}{4} & $1.813^{* * *}$ & $0.979^{* * *}$ & 0.183 \\
\hline & $(0.587)$ & $(0.325)$ & \\
\hline \multirow[t]{2}{*}{5} & $1.929^{* * *}$ & $0.902^{* * *}$ & 0.192 \\
\hline & $(0.567)$ & $(0.305)$ & \\
\hline \multirow[t]{2}{*}{6} & $2.063^{* * *}$ & $0.806^{* * *}$ & 0.188 \\
\hline & $(0.544)$ & $(0.279)$ & \\
\hline \multirow[t]{2}{*}{7} & $2.185^{* * *}$ & $0.714^{* * *}$ & 0.176 \\
\hline & $(0.521)$ & $(0.255)$ & \\
\hline \multirow[t]{2}{*}{8} & $2.318^{* * *}$ & $0.609^{* * *}$ & 0.149 \\
\hline & $(0.501)$ & $(0.231)$ & \\
\hline \multirow[t]{2}{*}{12} & $2.721^{* * *}$ & $0.283^{*}$ & 0.049 \\
\hline & $(0.436)$ & $(0.171)$ & \\
\hline \multirow[t]{2}{*}{16} & $2.953^{* * *}$ & 0.108 & 0.006 \\
\hline & $(0.348)$ & $(0.115)$ & \\
\hline
\end{tabular}

Notes: a. In parentheses are Newey and West (1987) heteroskedasticity and autocorrelation consistent standard errors corrected with twelve lags.

b. $* * *$ and $*$ denote statistically significant at the $1 \%$ and $10 \%$ level in a two-tailed test respectively.

c. Row $k$ is based on estimation for $t=1953:$ Q3 through 1998:Q3 $-k$. 
Table 2. Predicting the year-over-year growth in GDP using the yield spread

$$
\frac{1}{4}\left(y_{t+k}^{1}+y_{t+k-1}^{1}+y_{t+k-2}^{1}+y_{t+k-3}^{1}\right)=\alpha_{0}+\alpha_{1} \text { Spread }_{t}+\varepsilon_{t}
$$

\begin{tabular}{|c|c|c|c|}
\hline$k$ (quarters ahead) & $\hat{\alpha}_{0}$ & $\hat{\alpha}_{1}$ & $\bar{R}^{2}$ \\
\hline \multirow[t]{2}{*}{4} & $1.813^{* * *}$ & $0.979^{* * *}$ & 0.183 \\
\hline & $(0.587)$ & $(0.325)$ & \\
\hline \multirow[t]{2}{*}{5} & $1.962^{* * *}$ & $0.891^{* * *}$ & 0.156 \\
\hline & $(0.575)$ & $(0.309)$ & \\
\hline \multirow[t]{2}{*}{6} & $2.248^{* * *}$ & $0.693^{* * *}$ & 0.093 \\
\hline & $(0.549)$ & $(0.267)$ & \\
\hline \multirow[t]{2}{*}{7} & $2.517^{* * *}$ & $0.492^{* *}$ & 0.044 \\
\hline & $(0.542)$ & $(0.237)$ & \\
\hline \multirow[t]{2}{*}{8} & $2.834^{* * *}$ & 0.242 & 0.006 \\
\hline & $(0.530)$ & $(0.209)$ & \\
\hline \multirow[t]{2}{*}{9} & $3.104^{* * *}$ & 0.017 & -0.006 \\
\hline & $(0.518)$ & $(0.200)$ & \\
\hline \multirow[t]{2}{*}{10} & $3.319^{* * *}$ & -0.167 & 0.000 \\
\hline & $(0.531)$ & $(0.223)$ & \\
\hline \multirow[t]{2}{*}{11} & $3.492^{* * *}$ & -0.311 & 0.015 \\
\hline & $(0.545)$ & $(0.248)$ & \\
\hline \multirow[t]{2}{*}{12} & $3.584^{* * *}$ & -0.381 & 0.026 \\
\hline & $(0.528)$ & $(0.252)$ & \\
\hline \multirow[t]{2}{*}{13} & $3.623^{* * *}$ & $-0.406^{*}$ & 0.030 \\
\hline & $(0.485)$ & $(0.238)$ & \\
\hline \multirow[t]{2}{*}{14} & $3.628^{* * *}$ & $-0.399^{*}$ & 0.029 \\
\hline & $(0.423)$ & $(0.213)$ & \\
\hline \multirow[t]{2}{*}{15} & $3.635^{* * *}$ & $-0.400^{* *}$ & 0.029 \\
\hline & $(0.384)$ & $(0.200)$ & \\
\hline
\end{tabular}

Notes: a. In parentheses are Newey and West (1987) heteroskedasticity and autocorrelation consistent standard errors corrected with twelve lags.

b. $* * *, * *$ and $*$ denote statistically significant at the $1 \%, 5 \%$ and $10 \%$ level in a two-tailed test respectively.

c. Row $k$ is based on estimation for $t=1952: \mathrm{Q} 3+k$ through 1997:Q3. 
Table 3. Predicting future real GDP growth using the yield spread and lagged real GDP growth

$$
y_{t}^{k}=\alpha_{0}+\alpha_{1} \text { Spread }_{t}+\beta_{1} y_{t-1}^{1}+\beta_{2} y_{t-2}^{1}+\beta_{3} y_{t-3}^{1}+\beta_{4} y_{t-4}^{1}+\varepsilon_{t}
$$

\begin{tabular}{|c|c|c|c|c|c|c|c|}
\hline $\begin{array}{c}k \text { (quarters } \\
\text { ahead) }\end{array}$ & $\hat{\alpha}_{0}$ & $\hat{\alpha}_{1}$ & $\hat{\beta}_{1}$ & $\hat{\beta}_{2}$ & $\hat{\beta}_{3}$ & $\hat{\beta}_{4}$ & $\bar{R}^{2}$ \\
\hline \multirow[t]{2}{*}{1} & $1.281^{* *}$ & $0.763^{* * *}$ & $0.264^{* * *}$ & 0.077 & 0.003 & -0.064 & 0.134 \\
\hline & $(0.510)$ & $(0.296)$ & $(0.064)$ & $(0.075)$ & $(0.058)$ & $(0.083)$ & \\
\hline \multirow[t]{2}{*}{2} & $1.611^{* * *}$ & $0.863^{* *}$ & $0.193^{* * *}$ & 0.050 & -0.007 & $-0.105^{*}$ & 0.185 \\
\hline & $(0.586)$ & $(0.340)$ & $(0.060)$ & $(0.047)$ & $(0.048)$ & $(0.062)$ & \\
\hline \multirow[t]{2}{*}{3} & $1.848^{* * *}$ & $0.876^{* * *}$ & $0.141^{* *}$ & 0.028 & -0.054 & -0.070 & 0.194 \\
\hline & $(0.584)$ & $(0.332)$ & $(0.058)$ & $(0.048)$ & $(0.041)$ & $(0.050)$ & \\
\hline \multirow[t]{2}{*}{4} & $1.997^{* * *}$ & $0.880^{* * *}$ & $0.100^{*}$ & -0.015 & -0.037 & -0.056 & 0.200 \\
\hline & $(0.566)$ & $(0.331)$ & $(0.056)$ & $(0.038)$ & $(0.034)$ & $(0.043)$ & \\
\hline \multirow[t]{2}{*}{5} & $2.188^{* * *}$ & $0.835^{* * *}$ & 0.046 & -0.010 & -0.027 & -0.064 & 0.197 \\
\hline & $(0.541)$ & $(0.316)$ & $(0.049)$ & $(0.033)$ & $(0.028)$ & $(0.042)$ & \\
\hline \multirow[t]{2}{*}{6} & $2.313^{* * *}$ & $0.757^{* * *}$ & 0.031 & -0.010 & $-0.041^{*}$ & -0.045 & 0.191 \\
\hline & $(0.515)$ & $(0.289)$ & $(0.044)$ & $(0.029)$ & $(0.024)$ & $(0.039)$ & \\
\hline \multirow[t]{2}{*}{7} & $2.401^{* * *}$ & $0.684^{* * *}$ & 0.022 & -0.027 & -0.032 & -0.028 & 0.175 \\
\hline & $(0.494)$ & $(0.265)$ & $(0.040)$ & $(0.031)$ & $(0.022)$ & $(0.038)$ & \\
\hline \multirow[t]{2}{*}{8} & $2.521^{* * *}$ & $0.595^{* *}$ & 0.002 & -0.024 & -0.019 & -0.025 & 0.142 \\
\hline & $(0.482)$ & $(0.246)$ & $(0.042)$ & $(0.028)$ & $(0.024)$ & $(0.035)$ & \\
\hline \multirow[t]{2}{*}{12} & $2.973^{* * *}$ & 0.258 & 0.004 & -0.017 & -0.024 & -0.035 & 0.051 \\
\hline & $(0.420)$ & $(0.185)$ & $(0.033)$ & $(0.020)$ & $(0.018)$ & $(0.023)$ & \\
\hline \multirow[t]{2}{*}{16} & $3.141^{* * *}$ & 0.094 & -0.001 & -0.016 & -0.013 & -0.020 & -0.005 \\
\hline & $(0.305)$ & $(0.124)$ & $(0.024)$ & $(0.016)$ & (0.014) & $(0.020)$ & \\
\hline
\end{tabular}

Notes: a. In parentheses are Newey and West (1987) heteroskedasticity and autocorrelation consistent standard errors corrected with twelve lags.

b. $* * *, * *$ and $*$ denote statistically significant at the $1 \%, 5 \%$, and $10 \%$ level in a two tailed test respectively.

c. Row $k$ is based on estimation for $t=1954$ :Q3 through 1998:Q3 $-k$. 
Table 4. Predicting real GDP growth using the spread, current GDP growth, change in Federal funds rate, the growth of monetary aggregates, and oil price changes.

$$
y_{t}^{k}=\alpha_{0}+\alpha_{1} \text { Spread }_{t}+\delta_{1} y_{t-1}^{1}+\delta_{2} \Delta f f r_{t}+\delta_{3} M 1_{t}+\delta_{4} M 2_{t}+\delta_{5} o_{t}+\delta_{6} o_{t}^{*}+\varepsilon_{t}
$$

\begin{tabular}{|c|c|c|c|c|c|c|c|c|c|}
\hline$k$ (quarters ahead) & $\hat{\alpha}_{0}$ & $\hat{\alpha}_{1}$ & $\hat{\delta}_{1}$ & $\hat{\boldsymbol{\delta}}_{2}$ & $\hat{\delta}_{3}$ & $\hat{\delta}_{4}$ & $\hat{\boldsymbol{\delta}}_{5}$ & $\hat{\delta}_{6}$ & $\bar{R}^{2}$ \\
\hline \multirow[t]{2}{*}{1} & 0.018 & $0.775^{* *}$ & 0.108 & $0.611^{* *}$ & -0.037 & $1.162^{* * *}$ & $0.031^{* *}$ & $-0.124^{* *}$ & 0.186 \\
\hline & $(0.736)$ & $(0.330)$ & $(0.078)$ & $(0.293)$ & $(0.180)$ & $(0.184)$ & $(0.016)$ & $(0.061)$ & \\
\hline \multirow[t]{2}{*}{2} & 0.452 & $0.654^{* *}$ & $0.150^{*}$ & -0.128 & -0.069 & $0.973^{* * *}$ & $0.044^{* * *}$ & $-0.136^{* * *}$ & 0.279 \\
\hline & $(0.641)$ & $(0.265)$ & $(0.077)$ & $(0.191)$ & $(0.121)$ & $(0.195)$ & $(0.014)$ & $(0.046)$ & \\
\hline \multirow[t]{2}{*}{3} & 0.782 & $0.721^{* * *}$ & 0.087 & -0.033 & $-0.206^{*}$ & $0.966^{* * *}$ & $0.046^{* * *}$ & $-0.152^{* * *}$ & 0.324 \\
\hline & $(0.622)$ & $(0.267)$ & $(0.075)$ & $(0.194)$ & $(0.110)$ & $(0.187)$ & $(0.015)$ & $(0.042)$ & \\
\hline \multirow[t]{2}{*}{4} & $1.064^{*}$ & $0.717^{* * *}$ & 0.051 & -0.060 & $-0.302^{* * *}$ & $0.955^{* * *}$ & $0.036^{* *}$ & $-0.157^{* * *}$ & 0.381 \\
\hline & $(0.587)$ & $(0.265)$ & $(0.066)$ & $(0.203)$ & $(0.092)$ & $(0.161)$ & $(0.015)$ & $(0.041)$ & \\
\hline \multirow[t]{2}{*}{5} & $1.320^{* *}$ & $0.667^{* *}$ & 0.019 & -0.139 & $-0.290^{* * *}$ & $0.886^{* * *}$ & $0.034^{* *}$ & $-0.147^{* * *}$ & 0.383 \\
\hline & $(0.554)$ & $(0.264)$ & $(0.054)$ & $(0.189)$ & $(0.079)$ & $(0.138)$ & $(0.014)$ & $(0.039)$ & \\
\hline \multirow[t]{2}{*}{6} & $1.516^{* * *}$ & $0.610^{* *}$ & 0.007 & -0.176 & $-0.264^{* * *}$ & $0.792^{* * *}$ & $0.030^{* *}$ & $-0.122^{* * *}$ & 0.352 \\
\hline & $(0.567)$ & $(0.254)$ & $(0.051)$ & $(0.196)$ & $(0.075)$ & $(0.128)$ & $(0.013)$ & $(0.036)$ & \\
\hline \multirow[t]{2}{*}{7} & $1.837^{* * *}$ & $0.529^{* *}$ & -0.006 & -0.190 & $-0.262^{* * *}$ & $0.697^{* * *}$ & $0.026^{* *}$ & $-0.120^{* * *}$ & 0.338 \\
\hline & $(0.573)$ & $(0.231)$ & $(0.050)$ & $(0.176)$ & $(0.072)$ & $(0.122)$ & $(0.011)$ & $(0.035)$ & \\
\hline \multirow[t]{2}{*}{8} & $2.118^{* * *}$ & $0.435^{* *}$ & -0.016 & -0.218 & $-0.267^{* * *}$ & $0.628^{* * *}$ & $0.027^{* *}$ & $-0.118^{* * *}$ & 0.315 \\
\hline & $(0.552)$ & $(0.219)$ & $(0.050)$ & $(0.177)$ & $(0.072)$ & $(0.118)$ & $(0.011)$ & $(0.034)$ & \\
\hline \multirow[t]{2}{*}{12} & $2.885^{* * *}$ & 0.117 & -0.001 & $-0.254^{*}$ & $-0.174^{* *}$ & $0.310^{* *}$ & $0.019^{* *}$ & $-0.095^{* * *}$ & 0.175 \\
\hline & $(0.528)$ & $(0.164)$ & $(0.040)$ & $(0.130)$ & $(0.084)$ & $(0.154)$ & $(0.009)$ & $(0.031)$ & \\
\hline \multirow[t]{2}{*}{16} & $3.240^{* * *}$ & -0.033 & -0.004 & $-0.207^{* *}$ & $-0.145^{*}$ & $0.171^{* *}$ & $0.014^{*}$ & $-0.072^{* * *}$ & 0.098 \\
\hline & $(0.468)$ & $(0.121)$ & $(0.027)$ & $(0.103)$ & $(0.082)$ & $(0.135)$ & $(0.008)$ & $(0.027)$ & \\
\hline
\end{tabular}

Notes: a. $M 1_{t}$ and $M 2_{t}$ are the growth of monetary aggregates (M1 and M2) at time $t$.

b. In parentheses are Newey and West (1987) heteroskedasticity and autocorrelation consistent standard errors corrected with twelve lags.

c. $* * * * *$ and $*$ denote significantly different from zero at the $1 \%, 5 \%$ and $10 \%$ level in a twotailed test respectively.

d. Row $k$ is based on estimation for $t=1959$ :Q3 through 1998:Q3 $-k$. 
Table 5. Predicting real GDP growth using the decomposition of the yield spread,

$$
y_{t}^{k}=\gamma_{0}+\gamma_{1}\left(\frac{1}{n} \sum_{j=0}^{n-1} i_{t+j}^{1}-i_{t}^{1}\right)+\gamma_{2}\left(i_{t}^{n}-\frac{1}{n} \sum_{j=0}^{n-1} i_{t+j}^{1}\right)+\varepsilon_{t},
$$

using as instruments a constant, $i_{t}^{n}$ and $i_{t}^{1}$.

\begin{tabular}{|c|c|c|c|c|}
\hline$k$ (quarters ahead) & $\hat{\gamma}_{0}$ & $\hat{\gamma}_{1}$ & $\hat{\gamma}_{2}$ & $\begin{array}{c}\text { Test: } \chi_{1}^{2} \\
H_{0}: \gamma_{1}=\gamma_{2}\end{array}$ \\
\hline 1 & $\begin{array}{l}1.685^{* * *} \\
(0.654)\end{array}$ & $\begin{array}{l}1.614^{* * *} \\
(0.327)\end{array}$ & $\begin{array}{l}1.074^{* * *} \\
(0.331)\end{array}$ & $8.689^{* * *}$ \\
\hline 2 & $\begin{array}{l}1.583^{* * *} \\
(0.604)\end{array}$ & $\begin{array}{l}1.740^{* * *} \\
(0.291)\end{array}$ & $\begin{array}{l}1.163^{* * *} \\
(0.305)\end{array}$ & $11.096^{* * *}$ \\
\hline 3 & $\begin{array}{l}1.660^{* * *} \\
(0.577)\end{array}$ & $\begin{array}{l}1.691^{* * *} \\
(0.291)\end{array}$ & $\begin{array}{l}1.128^{* * *} \\
(0.301)\end{array}$ & $11.125^{* * *}$ \\
\hline 4 & $\begin{array}{l}1.745^{* * *} \\
(0.535)\end{array}$ & $\begin{array}{l}1.626^{* * *} \\
(0.262)\end{array}$ & $\begin{array}{l}1.082^{* * *} \\
(0.285)\end{array}$ & $10.539^{* * *}$ \\
\hline 5 & $\begin{array}{l}1.892^{* * *} \\
(0.484)\end{array}$ & $\begin{array}{l}1.495^{* * *} \\
(0.211)\end{array}$ & $\begin{array}{l}0.981^{* * *} \\
(0.263)\end{array}$ & $9.373^{* * *}$ \\
\hline 6 & $\begin{array}{l}2.063^{* * *} \\
(0.443)\end{array}$ & $\begin{array}{l}1.327^{* * *} \\
(0.168)\end{array}$ & $\begin{array}{l}0.865^{* * *} \\
(0.242)\end{array}$ & $7.411^{* * *}$ \\
\hline 7 & $\begin{array}{l}2.211^{* * *} \\
(0.407)\end{array}$ & $\begin{array}{l}1.172^{* * *} \\
(0.127)\end{array}$ & $\begin{array}{l}0.762^{* * *} \\
(0.220)\end{array}$ & $5.581^{* *}$ \\
\hline 8 & $\begin{array}{l}2.362^{* * *} \\
(0.386)\end{array}$ & $\begin{array}{l}1.004^{* * *} \\
(0.106)\end{array}$ & $\begin{array}{l}0.645^{* * *} \\
(0.202)\end{array}$ & $4.073^{* *}$ \\
\hline 12 & $\begin{array}{l}2.808^{* * *} \\
(0.375)\end{array}$ & $\begin{array}{l}0.484^{* * *} \\
(0.172)\end{array}$ & $\begin{array}{c}0.273 \\
(0.180)\end{array}$ & 1.313 \\
\hline 16 & $\begin{array}{l}3.056^{* * *} \\
(0.307)\end{array}$ & $\begin{array}{c}0.219 \\
(0.148)\end{array}$ & $\begin{array}{c}0.057 \\
(0.170)\end{array}$ & 0.898 \\
\hline
\end{tabular}

Notes: a. In parentheses are Newey and West (1987) heteroskedasticity and autocorrelation consistent standard errors corrected with twelve lags.

b. *** (except the fifth column) denotes statistically significant at the $1 \%$ and $5 \%$ level in a two tailed test respectively.

c. The figures in the fifth column are $\chi_{1}^{2}$ test statistics. *** and ** indicate rejection of the null hypothesis that the value of estimated coefficient of the future expected change of the short-term rate is equal to that of the term premium at the $1 \%$ and $5 \%$ level respectively.

d. All rows are based on estimation for $t=1953$ :Q3 through 1988:Q4. 
Table 6. Predicting real GDP growth using the interest rate volatility,

$$
y_{t}^{k}=\gamma_{0}+\gamma_{1}\left(\frac{1}{n} \sum_{j=0}^{n-1} i_{t+j}^{1}-i_{t}^{1}\right)+\gamma_{2}\left(i_{t}^{n}-\frac{1}{n} \sum_{j=0}^{n-1} i_{t+j}^{1}\right)+\gamma_{3} \hat{\sigma}_{t+1 \mid t}^{2}+\varepsilon_{t},
$$

using as instruments a constant, $i_{t}^{n}, i_{t}^{1}$, and $\hat{\sigma}_{t+1 \mid t}^{2}$.

\begin{tabular}{|c|c|c|c|c|}
\hline$k$ (quarters ahead) & $\hat{\gamma}_{0}$ & $\hat{\gamma}_{1}$ & $\hat{\gamma}_{2}$ & $\hat{\gamma}_{3}$ \\
\hline \multirow[t]{2}{*}{1} & 1.161 & $1.915^{* * *}$ & $1.091^{* * *}$ & 0.656 \\
\hline & $(0.821)$ & $(0.388)$ & $(0.354)$ & $(0.491)$ \\
\hline \multirow[t]{2}{*}{2} & 0.985 & $2.084^{* * *}$ & $1.182^{* * *}$ & $0.748^{* *}$ \\
\hline & $(0.769)$ & $(0.372)$ & $(0.349)$ & $(0.369)$ \\
\hline \multirow[t]{2}{*}{3} & 0.940 & $2.105^{* * *}$ & $1.152^{* * *}$ & $0.901^{* * *}$ \\
\hline & $(0.735)$ & $(0.361)$ & $(0.353)$ & $(0.335)$ \\
\hline \multirow[t]{2}{*}{4} & $1.211^{*}$ & $1.933^{* * *}$ & $1.099^{* * *}$ & $0.668^{* *}$ \\
\hline & $(0.684)$ & $(0.331)$ & $(0.319)$ & $(0.295)$ \\
\hline \multirow[t]{2}{*}{5} & $1.482^{* *}$ & $1.731^{* * *}$ & $0.995^{* * *}$ & $0.513^{*}$ \\
\hline & $(0.612)$ & $(0.276)$ & $(0.288)$ & $(0.266)$ \\
\hline \multirow[t]{2}{*}{6} & $1.800^{* * *}$ & $1.479^{* * *}$ & $0.874^{* * *}$ & 0.329 \\
\hline & $(0.534)$ & $(0.220)$ & $(0.256)$ & $(0.208)$ \\
\hline \multirow[t]{2}{*}{7} & $2.077^{* * *}$ & $1.249^{* * *}$ & $0.767^{* * *}$ & 0.168 \\
\hline & $(0.482)$ & $(0.180)$ & $(0.226)$ & $(0.205)$ \\
\hline \multirow[t]{2}{*}{8} & $2.282^{* * *}$ & $1.050^{* * *}$ & $0.648^{* * *}$ & 0.100 \\
\hline & $(0.447)$ & $(0.151)$ & $(0.205)$ & $(0.194)$ \\
\hline \multirow[t]{2}{*}{12} & $2.644^{* * *}$ & $0.579^{* *}$ & 0.279 & 0.206 \\
\hline & $(0.456)$ & $(0.241)$ & $(0.191)$ & $(0.196)$ \\
\hline \multirow[t]{2}{*}{16} & $2.792^{* * *}$ & 0.371 & 0.065 & 0.331 \\
\hline & $(0.397)$ & $(0.228)$ & $(0.198)$ & $(0.232)$ \\
\hline
\end{tabular}

Notes: a. In parentheses are Newey and West (1987) heteroskedasticity and autocorrelation consistent standard errors corrected with twelve lags.

b. $* * *, * *$, and $*$ denote significantly different from zero at the $1 \%, 5 \%$ and $10 \%$ level in a twotailed test respectively.

c. All rows are based on estimation for $t=1953: \mathrm{Q} 3$ through 1988:Q4. 